\title{
Evaluation of Antibiotic Potential of Crude Culture Extract of Lactic Acid Bacteria on Multi-Drug Resistance Farm Animal Pathogens
}

\author{
Abdulkadir Musliu*, Sulaimon Adebisi, Samira Arzika \\ Department of Science Technology, Waziri Umaru Federal Polytechnic, BirninKebbi, Nigeria \\ Email address: \\ musille2003@yahoo.com (A. Musliu) \\ ${ }^{*}$ Corresponding author \\ To cite this article: \\ Abdulkadir Musliu, Sulaimon Adebisi, Samira Arzika. Evaluation of Antibiotic Potential of Crude Culture Extract of Lactic Acid Bacteria on \\ Multi-Drug Resistance Farm Animal Pathogens. Advances in Bioscience and Bioengineering. Vol. 9, No. 2, 2021, pp. 20-24. \\ doi: 10.11648/j.abb.20210902.11
}

Received: April 15, 2021; Accepted: May 7, 2021; Published: May 20, 2021

\begin{abstract}
The present study evaluate the antibiotic potential of crude culture extract of lactic acid bacteria on multi-drugs resistance farm animal pathogen. Eight (8) different pathogens associated with Farm animals were used in this study. The pathogens were collected from different part of the body of different animal which include, Vagina of cow, Stool of cow; Male cow anus; Vagina of sheep; Vagina of goat, Male Goat Anus, Penis of goat and Female goat anus. The Confirmation of Pathogens, Isolation of crude extract of Lactic acid bacteria, Cell Free Supernatant and determination of antibacterial activity was done using standard method. The results show that Streptococcus agalactiae VIS, Staphylococcus aureus STC and Escherichia coli VRC were resistance to 4 out of 13 antibiotics. While Staphylococcus aureus FGA, and Escherichia coli (PEG, MGA and VRG) were resistances to 3 out of 13 antibiotic tested. Staphylococcus aureus MCA is sensitive to all antibiotics tested. Clear zone of inhibition was observed in both the Crude Culture Extract (CCE) and Cell Free Supernatant (CFS) of Lactic Acid Bacteria which ranged from $7 \mathrm{~mm}$ to $25 \mathrm{~mm}$. The results further revealed that both Crude Culture Extract (CCE) and Cell Free Supernatant (CFS) of Lactic Acid Bacteria can be used in the in the treatment of multidrug resistance of pathogens. The isolation process of Crude Culture Extract (CCE) and it uses as an antibacterial agent is a simple process that do not required the use of any sophisticated equipment and techniques, thus it may be use in the treatment of multidrug resistance pathogens in both local and modern animal farms.
\end{abstract}

Keywords: Antibiotic, Lactic Acid Bacteria, Pathogens, Multidrug Resistance, Animals

\section{Introduction}

Over the past years, antibiotics have been used in the process and production of farm animal as therapeutic agents to treat bacterial infections that often decrease performance and cause diseases to the animals. Many of the antibiotics used in the animal production and industry have been used in human medicine as well. As the widespread use of antibiotics in the animal industries becomes necessary, the antibiotics were placed under increased scrutiny during usage because of concern over development of bacterial resistance to the usual microbiocidal effects of the antibiotics. Ever since their first usage in animals, there has been a cause for concern about the use of antibiotics in poultry and livestock production [11].
However, there was a spread awareness that bacterial resistance was not due to single but to multiple antibiotics and as a result, this finally resulted in the ban on the use of sub-therapeutic dose of certain antibiotics in animal [8]. The antimicrobial resistance has become one of the main safety issues for humanity, and several organizations, such as the World Health Organization (WHO), the Food and Agriculture Organization (FAO), the US Food and Drug Administration (FDA), and the European Food Safety Authority (EFSA) among others, have raised an awareness on this issue. The antimicrobial resistance can take place when microorganisms (bacteria, fungi, viruses, and parasites) are continuously exposed to antimicrobials (antibiotics, antivirals, antifungals, etc.), [10] and as a result of an 
adaptation process, some microorganisms can survive and grow in the presence of the antimicrobial, which in normal conditions would inactivate them [7].

However, the use of antibiotics as drugs that treats bacterial infections in humans and animals, preventing the reproduction of bacteria or inactivating them through several mechanisms, either inhibiting the synthesis of the cell wall or the cytoplasmic membrane, blocking the protein synthesis or the DNA copying processes, altering the metabolism, or acting directly against the bacterial resistance pathway were discovered [6]. Utilization of antibiotics such as (cephalosporins, broad-spectrum penicillin's, and fluoroquinolones) in humans has increased $36 \%$ from the years 2000 to 2010, mainly due to their inappropriate prescription and consumption for the treatment of viral instead of bacterial infections [1].

The antimicrobial resistance involves several mechanisms associated to the presence of resistant genes that allow the direct inactivation of the active antimicrobial molecule as well as the loss of susceptibility to the antimicrobial by modification of the target site or reduction of the antimicrobial uptake [8]. As a result, antimicrobials become ineffective, and resistant microorganisms can survive and transfer their resistant machinery to other micro-organisms and become a threat to public health. The presence of antimicrobial-resistant microorganisms not only affects both the human and animal health but also increases the risk for spread and contamination of foods, crops, livestock, and aquaculture [4].

In humans and animals, the increasing antibiotic use gave rise to an increase in antibiotic resistance. Because resistant bacteria can be transmitted between humans and animals through contact, food products and the environment, the use of antibiotics in animals plays a role in human health [5]. More antibiotics are used in agriculture, often to promote growth or prevent disease than to treat sick animals. Many of this agents commonly given to animals are the same antibiotics relied upon to treat human infections, raising concerns about depleting the effectiveness of these agents at the expense of human health [11].

There are several data available about the widespread use of antibiotics in agriculture and that antibiotic resistance is a major problem to farm animal production in Nigeria. This in turns has reduced the amount of antibiotics used in agriculture and phasing out the nontherapeutic use of antibiotics in animals if possible without jeopardizing animal health and will contribute to reducing the burden of antibiotic-resistant infections [2]. Thus the present study focus on Evaluation of antibiotic potential of crude culture extract of Lactic acid bacteria on Multi-drug resistance farm animal pathogens.

\section{Methods}

\subsection{Source of Microorganisms}

Cultures lactic acid bacteria were obtained from Microbiological laboratory, Waziri Umaru Federal
Polytechnic, 8 (eight) pathogens associated with Farm animals were also obtained from same laboratory.

\subsection{Confirmation of Isolates}

Lactic acid bacteria were subcultured into a selective medium, De man, Rogosa and Shape (MRS) agar. The confirmation of the isolates were done base on their morphology and cultural characteristics. Further confirmation was made using catalase test. The pathogens were subcultured in blood agar and incubated at $37^{\circ} \mathrm{C}$ for 24 hours after which the isolates that produce hemolytic zone on the blood agar were confirmed as pathogen.

\subsection{Antibiotic Susceptibility Test}

The disk-diffusion method was used. This involves impregnating small disks of standard filter with given amounts of a chosen range antibiotics: Ampicillin, Tetracycline, Penicillin, Cotrimazole, Ciprofloxacin, Levofloxacin, Cephalexin, Ofloxacin, Zinacef, Pefloxacin, Erythromycin, Augmentin (conforming to Mcfarland turbidity standard). These were placed on plates of culture medium previously spread uniformly with the inoculum of the bacterial isolate to be tested and are incubated at $37^{\circ} \mathrm{C}$ for 24 hours. After incubation, the degree of sensitivity was determined by measuring the visible areas (zones) of inhibition of growth produced by the diffusion of the antibiotics from the disks into the surrounding medium [17].

\subsection{Evaluation of Antimicrobial Activity Against the Pathogensusing Agar Well Diffusion Assay}

This was conducted according to the modified method of [17]. Targeted colony was diluted using $0.1 \%$ peptone water and are vortexed to obtain $0.5 \mathrm{McF}$ arland Turbidity Standard. All pathogenic bacteria used were freshly streaked onto Muller Hilton Agar (Merck, Germany) respectively using Kirby Bauer technique. Then, $5 \mathrm{~mm}$ diameter size of well were immediately made up in each plates and $20 \mu \mathrm{l}$ molten agar be poured to each well until solidified. Immediately, 80 $\mu l$ of crude culture extract and cell free supernatant from each LAB strains were transferred to each well separately. Each plate was controlled by adding with sterilized peptone water. All plates were incubated at $37^{\circ} \mathrm{C}$ for $24 \mathrm{~h}$. For measurements, the zones of inhibition were measured from the edges of the last visible antimicrobial inhibition growth without deducted with the size of the LAB well (Kirby Bauer). The ruler was positioned across the center of the well to make these measurements. The pathogenic bacteria without LAB cultures were used as control of experiments. The experiments were conducted twice in order to obtain the average mean of diameter of inhibitory zone. The bacteria will be classifies as sensitive or resistance to antibiotics according to the interpretive standard of Clinical and Laboratory Standards Institute (CLSI). 


\section{Results}

Table 1. Collected pathogens, their Sources and their Code from Food Producing Animal.

\begin{tabular}{ll}
\hline Sources of isolates from farm animal & Isolates codes \\
\hline COW & \\
Vagina cow & VAC \\
Stool cow & STC \\
Male cow anus & MCA \\
SHEEP & \\
Vagina sheep & VIS \\
GOAT & \\
Vagina goat & VRG \\
Male Goat Anus & MGA \\
Penis goat & PEG \\
Female goat anus & FGA \\
\hline
\end{tabular}

Table 2. Susceptibility pattern of isolated pathogens towards antibiotics using disk diffusion test (DDT).

\begin{tabular}{lllll}
\hline Antibiotics & Streptococcus agalactiae VIS & Staphylococcus aureus STC & Staphylococcus aureus FGA & Escherichia coli PEG \\
\hline Septrin $(30 \mu \mathrm{g})$ & - & + & + & + \\
Chloramphenicol $(30 \mu \mathrm{g})$ & + & + & + & + \\
Sparfloxacin $(10 \mu \mathrm{g})$ & + & + & + & + \\
Ciprofloxacin $(10 \mu \mathrm{g})$ & + & + & + & + \\
Amoxacilin $(30 \mu \mathrm{g})$ & + & - & - & - \\
Argumentin $(30 \mu \mathrm{g})$ & + & + & + & + \\
Gentamycin $(10 \mu \mathrm{g})$ & + & + & + & + \\
Pefloxacin $(30 \mu \mathrm{g})$ & + & + & + & + \\
Streptomycin $(30 \mu \mathrm{g})$ & + & + & - & - \\
Ampliclox $(30 \mu \mathrm{g})$ & - & - & + & + \\
Zinnacef $(20 \mu \mathrm{g})$ & - & - & - & - \\
Rocephin $(25 \mu \mathrm{g})$ & - & - & + & + \\
Erythromycin $(30 \mu \mathrm{g})$ & + & + & & \\
\hline
\end{tabular}

Table 2. Continued.

\begin{tabular}{lllll}
\hline Antibiotics & Escherichia coli MGA & Escherichia coli VRG & Staphylococcus aureus MCA & Escherichia coli VRC \\
\hline Septrin $(30 \mu \mathrm{g})$ & + & + & + & + \\
Chloramphenicol $(30 \mu \mathrm{g})$ & + & + & + & - \\
Sparfloxacin $(10 \mu \mathrm{g})$ & + & + & + & + \\
Ciprofloxacin $(10 \mu \mathrm{g})$ & + & + & + & + \\
Amoxacilin $(30 \mu \mathrm{g})$ & - & - & + & + \\
Argumentin $(30 \mu \mathrm{g})$ & + & + & + & - \\
Gentamycin $(10 \mu \mathrm{g})$ & + & + & + & + \\
Pefloxacin $(30 \mu \mathrm{g})$ & + & + & + & + \\
Streptomycin $(30 \mu \mathrm{g})$ & + & + & + & - \\
Ampliclox $(30 \mu \mathrm{g})$ & + & - & + & \\
Zinnacef $(20 \mu \mathrm{g})$ & - & + & + & + \\
Rocephin $(25 \mu \mathrm{g})$ & - & - & + & + \\
Erythromycin $(30 \mu \mathrm{g})$ & + & + & + & + \\
\hline
\end{tabular}

Key: + = Positive; - = Negative; VAC = Vagina cow, STC = Stool cow; MCA = Male cow anus; VIS = Vagina sheep; VRG =Vagina goat, MGA = Male Goat Anus, $\mathrm{PEG}=$ Penis goat, $\mathrm{FGA}=$ Female goat anus

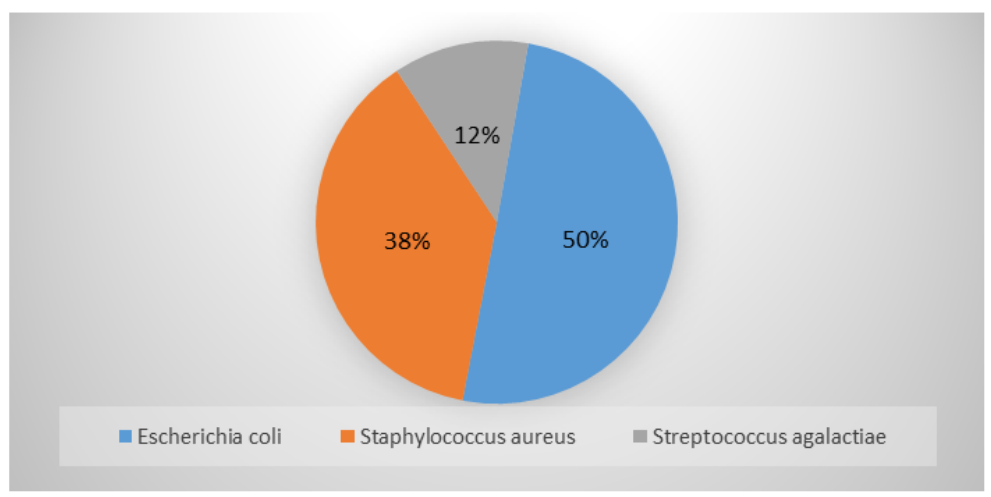

Figure 1. Percentage of occurrence of isolates as pathogens. 


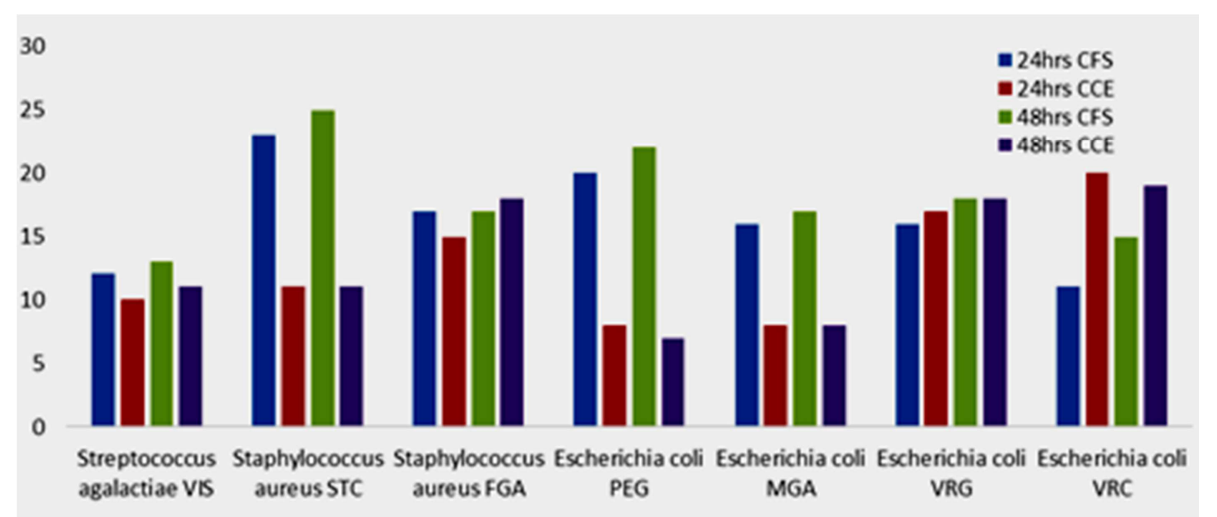

Key: Crude Culture Extract (CCE) and Cell Free Supernatant (CFS) of Lactic Acid Bacteria. (Diameter of zone of inhibition measured in (mm)

Figure 2. Inhibition of the test pathogens by crude culture extract.

\section{Discussion}

The collected pathogens shown in table 1 above were sourced from different part of the body of different animal which include, Vagina of cow, Stool of cow; Male cow anus; Vagina of sheep; Vagina of goat, Male Goat Anus, Penis of goat and Female goat anus.

The results of susceptibility pattern of isolated pathogens towards different antibiotics using disk diffusion test (DDT) were shown in table 2 above. Results shows that Streptococcus agalactiae, Staphylococcus aureus and Escherichia coli collected from vagina sheep, stool cow and vagina of cow were resistance to 4 out of 13 antibiotics tested respectively. While Staphylococcus aureus collected fromFemale goat anus, and Escherichia coli collected frompenis of goat, male goat anus and vagina goat were resistances to 3 out of 13 antibiotic tested. Staphylococcus aureus collected from male cow anus is sensitive to all antibiotics tested. The results revealed that that all the isolate are multidrug resistance except Staphylococcus aureus collected from male cow anus [15] reported that multidrug resistance was confirm only when the isolate is resistant to at least three or more antibiotics. The results further revealed that locations of isolates in the body had no or very little effects on the antibiotics resistance of the isolates, which is in line with [14].

Figure 1 shows that Escherichia coli (50\%) had the highest Percentage of occurrence as pathogens, which is followed by Staphylococcus aureus with 38\%. While Streptococcus agalactiae $(12 \%)$ had the least Percentage of occurrence. Results shows that all the three isolates are pathogenic. This is in accordance with [3] who reported all the three isolates as pathogenic.

The results in Figure 2 shows Inhibition of the test pathogens by crude culture extract. It shows that the higher zone of Inhibition was achieved in both the Crude Culture Extract (CCE) and Cell Free Supernatant (CFS) of LAB which ranged from $7 \mathrm{~mm}$ to $25 \mathrm{~mm}$. It also shows that Cell Free Supernatant (CFS) of LAB had the highest zone of Inhibition in all the isolates tested, which ranged from $13 \mathrm{~mm}$ to $25 \mathrm{~mm}$ at 48 hours' period and $12 \mathrm{~mm}$ to $23 \mathrm{~mm}$ at 24 hours'period. However, the least zone of Inhibition was observed in Crude Culture Extract (CCE) of Lactic Acid Bacteria, which shows the zone of Inhibition in all the isolates ranged from $7 \mathrm{~mm}$ to $19 \mathrm{~m}$ at 48 hours and from $8 \mathrm{~mm}$ to $20 \mathrm{~m}$ at 24 hours period. The results further revealed that both Crude Culture Extract (CCE) and Cell Free Supernatant (CFS) of LAB can be used in the in the treatment of multidrug resistance of pathogens. But Cell Free Supernatant (CFS) of LAB is more effective. This study agrees with the study of $(12,13)$. They confirm the use of Crude Culture Extract (CCE) and Cell Free Supernatant (CFS) of LAB in the treatment of bacterial pathogens.

\section{Conclusion}

The antibiotic potential on crude culture extract of lactic acid bacteria on multi-drugs resistance on farm animal pathogen was evaluated in this study. The study revealed that Streptococcus agalactiae, Staphylococcus aureus and Escherichia coli were multidrug resistance pathogenic bacteria. Also it revealed that Escherichia coli had the highest occurrence as a pathogenic bacteria when compared with Streptococcus agalactiae and Staphylococcus aureus. Base on the antibiotic activity of Crude Culture Extract (CCE) and Cell Free Supernatant (CFS) of Lactic Acid Bacteria tested in this study against multidrug resistance pathogenic bacteria. The study revealed that both Crude Culture Extract (CCE) and Cell Free Supernatant (CFS) of LAB had higher zone of Inhibition and can be used in the treatment of multidrug resistance of pathogens.

\section{Recommendations}

Proper measures, likeenvironmental sanitation and the use of disinfectant need to be put in place so as to prevent the occurrence of pathogenic bacteria. The isolation process of Crude Culture Extract (CCE) and Cell Free Supernatant (CFS) and it used as an antibacterial agents is a simple process that do not required the use of external techniques, Thus it use in the treatment of multidrug resistance pathogens in both local and modern farmers is also recommended. Finally, the is need for further studies on antibiotic potentials 
of Crude CultureExtract (CCE) and Cell Free Supernatant (CFS) of LAB against other pathogenic bacteria, viruses and parasite, so as to explore more facts.

\section{References}

[1] Clavo, L., Parker, K., Blumenthal, D. and Buxton, 1. (2009): Goodman and Gilman's Manual of Pharmacology and Therapeutics. International Edition, McGraw-Hill, New York, Pp. 707-797.

[2] Dowlin, K., Nakasaki, K., Yanagisawa, M. and Kobayashi, K. (2017). Microbiological quality of fermented milk produced by repeated-batch culture. Journal of Bioscience andBioengineering, 105, 73-76.

[3] Dutta, T. K., Roychoudhury, P., Bandyopadhyay, S., and Chandra, R. (2011). "Detection and Characterization of Shiga Toxigenic Escherichia Coli from Piglets with or without Diarrhoea in Mizoram." The Indian Journal of Animal Sciences 81 (9).

[4] Fraqueza, Y. (2015). Impact of small scale fermentation technology on food safety in developing countries. International Journal of Food Microbiology, 75, 213-229.

[5] Gad, E., Leroy, F. and De Vuyst, L. (2014). Lactic acid bacteria as functional starter cultures for the food fermentation industry. Trends in Food Science and Technology, 15, 67-78.

[6] Ghatak, S., Singha, A., Sen, A., Guha, C. Ahuja, A. Bhattacharjee, U. and Das, S. (2013). "Detection of New Delhi Metallo-Beta-Lactamase and Extended-Spectrum BetaLactamase Genes in Escherichia Coli Isolated from Mastitic Milk Samples." Transboundary and Emerging Diseases 60 (5): $385-89$.

[7] Hemlata, F., Fu, G. and Tuy, D., (2015). "Enumeration and Antibiotic Resistance Pattern of Staphylococcus Aureus from Raw Chicken Meat Sold in Bikaner City." Journal of Pure and Applied Microbiology 9 (2).

[8] Jasmer, D. P., Goverse, A. and Smant, G. (2003). Parasitic nematode interactions with mammals and plants. Annual Review of Phytopathology. 41: 245-270.

[9] Kamal, M., Charton, J., Ballard, K., Latinovic, R. and Gulliford, M. (2015): Variations in antibiotic prescribing and consultation rates for acute respiratory infection in UK practices 1995-2000. British Journal of General Practice, 55: 603-608.

[10] Karamanis, E. M., Mathaiou, D. K., Moraitis, L. I., and Falagas, M. E. (2008): Fluoroquinolones versus beta-lactam base regimens for the treatment of osteomyelitis: a metaanalysis of randomized controlled trials. Spine, 33: E297E304.

[11] Kumar, R., Yadav, B. R., Anand, S. K. and Singh, R. S. (2011). "Molecular Surveillance of Putative Virulence Factors and Antibiotic Resistance in Staphylococcus aureus Isolates Recovered from Intra-Mammary Infections of River Buffaloes." Microbial Pathogenesis 51 (1-2): 31-38.

[12] Okaiyeto S. O., Salami O. S., Dnbirni S. A., Allam L. and Onoja, I. I. (2012). Clinical, Gross and Histopathological Changes Associated With Chronic Fasciolosis Infection in a Dairy Farm. Journal of veterinary advances, 2 (8): 444-448.

[13] Pan, D. and Yu, G. (2014). The relative effect of milk base, starter, and process on yogurt texture: A review. Critical Reviews in FoodScience and Nutrition, 44, 113-137.

[14] Singh, B. R., Jyoti, J., Chandra, M., Babu, N. and Sharma, G. (2009). "Drug Resistance Patterns of Salmonella Isolates of Equine Origin from India." The Journal of Infection in Developing Countries 3 (02). 67.

[15] Tiwari, J. G., Chaudhary, S. P., Tiwari, H. K., Dutta, T. K., Saikia, P. and Hazarika, P. (2011). "Microbial Evaluation of Market Milk and Milk-Products of Mizoram, India with Special Reference to Staphylococcus Aureus." The Indian Journal of Animal Sciences 81 (4).

[16] WHO (2015). Global strategy for containment of antimicrobial resistance.

[17] Zhao, G. and Kim, F. (2011). Polyphasic characterization of the lactic acid bacteria in kefir. Systematic and Applied Microbiology, 29, 59-68. 